\title{
Synthesis of Some Derivatives of 4-phenyl-1,3-dihydro-2H-imidazole-2-thion Using Ionic Liquid as Catalyst and Evaluation of Their Antimicrobial Activity
}

\author{
Bahareh Behmaram ${ }^{1}$, Naser Foroughifar ${ }^{2}$, Neda Foroughifar ${ }^{3}$, Sara Hallajian ${ }^{4}$ \\ ${ }^{1}$ Department of Applied Chemistry, Faculty of Pharmaceutical Chemistry, Pharmaceutical Sciences Branch, Islamic Azad \\ University, Tehran-Iran (IAUPS) \\ ${ }^{2}$ Department of Chemistry, Tehran North Branch, Islamic Azad University, Tehran-Iran \\ ${ }^{3}$ Division of Diabetes, Endocrinology and Metabolism, Faculty of Medicine, Imperial College London, London W12 \\ ONN, UK \\ ${ }^{4}$ Department of Pharmaceutical Chemistry, Faculty of Pharmaceutical Chemistry, Pharmaceutical Sciences Branch, \\ Islamic Azad University, Tehran-Iran (IAUPS) \\ Correspondence: Naser Foroughifar, Department of Chemistry, Tehran North Branch, Islamic Azad University, Tehran, \\ Iran. E-mail: n_foroughifar@yahoo.com
}

Received: January 20, 2017 Accepted: March 5, $2017 \quad$ Online Published: March 20, 2017

doi:10.5539/ijc.v9n2p45

URL: https://doi.org/10.5539/ijc.v9n2p45

\begin{abstract}
The synthesis of some 1,3-diazoles and thiazoles was realized in different conditions:

a) In the presence of PTSA or sulfuric acid as catalyst we obtained only diazole products(4a-d).

b) In basic medium such as DABCO or sodium hydroxide and ionic liquid afforded thiazoles.

c) Both products, diazoles and thiazoles were collected when using methanol as catalyst and solvent.

All structures were confirmed by IR, ${ }^{1} \mathrm{H}$ NMR and ${ }^{13} \mathrm{C}$ NMR spectroscopy. The antibacterial activity of some synthesized compounds was investigated against Escherichia Coli (ATCC: 25922) and Serratia marcescens (ATCC: 13880) as gram negative bacteria, Bacillus sabtilis (ATCC: 6633) and Staphylococcus aureus (ATCC: 6338) as gram positive bacteria. Some of these products exhibit good activities to significant antibacterial activity.
\end{abstract}

Keywords: 1,3-diazole, thiazole, heterocycle, ionic liquid, antimicrobial activity

\section{Introduction}

Diazoles and thiazoles have been attracting special interest because of their various biological activities and clinical applications (Holla, Malini, Rao, Sarojini, \& Kumari, 2003).

Heterocyclic compounds containing a 1,3-diazole nucleus are of special interests thanks to their applications in medicinal chemistry as they are the basic skeleton of several bioactive compounds such as antifungal, antibacterial, antitumor and antitubercular (Holla, Malini, Rao, Sarojini, \& Kumari, 2003).

1,3-diazole is an organic aromatic five-membered heterocyclic compound which is known with the formula $\mathrm{C}_{3} \mathrm{H}_{4} \mathrm{~N}_{2}$ (Chawla, Sharma, \& kumar Sharma, 2012). This ring system and its derivatives are found in critical medicinal building blocks such as histamine, biotin, histidine and in many natural products, because this ring system is able to form the hydrogen bond and also there is a non-shared electron pair of nitrogen in this compound (Safari, Akbari, \& Naseh,2012; Shalini, Kumar Sharma, Kumar 2010; Ashish, \& Pandeya, 2011). This compound is found to be associated with various medicinal properties including anticancer, b-lactamase inhibitors, carboxy peptidase inhibitors, hemoxygenase inhibitors, anti-aging agents, anticoagulants, anti-inflammatory, antibacterial, anti-fungal, antiviral, antitubercular, antidiabetics, antimalarial (Shalini et al., 2010), and antibacterial effect on pathogens such as E. taecalis, E.coli, and S. aureus (Ghasemi, Beyzaei, Hashemi, \& Majidiani, 2016).

1, 3-diazoles and its derivatives were synthesized by different methods. Common approaches of this synthesis include Debus synthesis, Radiszewski synthesis, dehydrogenation of imidazolines, from alpha halo ketones, Wallach synthesis, Marckwald synthesis, from amino nitrile and aldehyde (Chawla et al., 2012; Ashish at al., 2011). 
Thiazole ring is an important motif in active biological compounds such as B 1 vitamin (Bakavoli, Beyzaie, Rahimizadeh, Eshghi, \& Takjoo 2009, Yavari, Sayyed-Alangi, Hajinasiri, \& Sajjadi-Ghotbabadi, 2009; Afradi, Foroughifar, Pasdar, \& Moghanian, 2016). This heterocyclic system and its derivatives show various properties as drugs for the treatment of cancer (Afradi et al., 2016), blood cholesterol, blood pressure, and HIV virus infection (Ghasemi et al., 2016; Yavari et al., 2009), they're also featured strongly antibacterial, antifungal and anti- inflammatory activities (Mishra, Tomer, Priyanka, Sharma, Jha, 2012; Afradi et al., 2016).

According to researches, this critical scaffold can inhibit antibacterial activities of S. aureus and E. coli pathogens (Ghasemi et al., 2016).

Diverse procedures have been investigated to synthesize thiazole ring and its derivatives. These methodologies include Cook_Heilborn, Tchernic and Hatzsch which is the most common one and is carried out by the reaction of $\alpha$-halo carbonyl compounds with thiourea or thioamids (Yavari et al., 2009; Ghodse \& Telvekar, ,2015; Ayati, Emami, Asadipour, Shafiee, \& Foroumadi, 2015).

Despite the variety of mentioned methods for1,3-diazole and thiazole synthesis, several drawbacks have been reported which include high temperatures, long reaction time, low yields, the requirement of using toxic organic solvents and/or catalysts (Yavari et al., 2009; Narender, Reddy Somi, Sridhar, Nageswar, \& Rao Rama, 2005).

Ionic liquids (ILs) are defined as ionic salts with a melting point below $100^{\circ} \mathrm{C}$, a high polarity and low vapor pressure (Yavari et al., 2009). These salts are formed of organic cation and inorganic anions (Ratti, 2014). Ionic liquids have been applied widely as alternative solvents to support green chemistry considering particular physical and chemical properties (Selva, Perosa, Guidi, \& Cattelan, 2016).

Besides this common usage, ILs appear to be applied as green catalysts for the replacement of conventional catalysts (Ratti, 2014; Olivier-Bourbigou, Magna, \& Morvan, 2010; Zhao, Wu, Kou, \& Min, 2002).

Due to the functional groups of the cation or anion in ILs, they can be considered as acidic, basic or organic catalysts (Ratti, 2014).

In the present research, we have synthesized some of new derivatives of 1,3-diazoles and thiazoles using water as green and environment friendly solvent and different catalysts such as ionic liquid. The purpose of this study was to investigate the antibacterial activity of the new derivatives comparing to two known antibiotics.

\section{Experimental}

\subsection{Materials and Equipment}

Melting points were determined with an Electrothermal digital apparatus (Thermo Scientific) and were uncorrected. IR spectra were obtained on Shimadzu FT-IR 5000 spectrophotometer in KBr. NMR spectra were recorded on a Brucker 500 and $300 \mathrm{MHz}$ spectrometer, chemical shifts were given in ppm in DMSO-d6.

The derivatives of acetophenone (2, 2', 4'-trichloro acetophenone; 2-bromo acetophenone; 2, 4'-dibromo acetophenone; 2- chloro-3', 4'-dihydroxy acetophenone; 2- bromo- 4'-methoxy acetophenone), thiourea were used as reactants. DABCO, PTSA, sulfuric acid, sodium hydroxide, methanol, ionic liquid catalyst were applied as catalysts, and distilled water was used as the solvent. N-hexane, ethyl acetate were applied as an eluent in thin layer chromatography. All chemical materials were purchased from Merck and Sigma-Aldrich.

\subsection{Procedure for the Synthesis of 1,3-Diazoles and Thiazoles}

Acetophenone derivatives $(1 \mathrm{mmol})$, thiourea $(1 \mathrm{mmol})$ and PTSA, DABCO, or sulfuric acid (6-7 drops) as catalysts were transferred to a $100 \mathrm{~mL}$ 2-neck round bottom flask and $20 \mathrm{~mL}$ distilled water was added as the solvent. Then the mixture was reacted under reflux conditions. The progress of the reaction was monitored by TLC using n-hexane/ ethyl acetate (1/1). After completion of the reaction, the reaction mixture was cooled at room temperature to obtain a precipitate which is considered as the product.

All the steps above were then carried out with 2 types of acetophenone derivatives (1mmol) (2-chloro- 3', 4'- dihydroxy acetophenone; 2, 2', 4'-trichloro acetophenone) and thiourea and ionic liquid catalyst and water as the solvent.

Then finally, 2-chloro-3',4'-dihydroxy acetophenone $(1 \mathrm{mmol})$ and 2,4'-dibromo acetophenone and thiourea were respectively reacted with methanol and sodium hydroxide $(20 \mathrm{~mL})$ under reflux conditions. Monitoring the reaction progress and precipitation were carried out as before.

\subsection{Ionic Liquid Catalyst Synthesis}

Choline chloride and urea $(2 \mathrm{mmol})$ were heated and stirred for 2 hours. Then the reaction mixture was cooled and the desired product (choline chloride urea) was gained. 


\subsection{Antibacterial Activities of Synthesized Compounds}

Four microorganisms were used to test the antibacterial activity of the synthesized compounds. They were: Escherichia Coli (ATCC: 25922) and Serratia marcescens (ATCC: 13880) as gram negative bacteria and Bacillus sabtilis (ATCC: 6633), and Staphylococcus aureus (ATCC: 6338) as gram positive bacteria. Antibacterial activities of the compounds were tested by Disc Diffusion method and Minimum Inhibitory Concentration (MIC) using agar dilution method.

\subsection{Characterization Data of the Compounds}

\subsubsection{5-(2',4'-dichloro phenyl)-thiazole 2-amine (3a)}

Pale yellow solid; m.p. $208{ }^{\circ} \mathrm{C}-217^{\circ} \mathrm{C}$; Yield 88\%. ${ }^{1} \mathrm{H}-\mathrm{NMR}$ (DMSO, $\left.500 \mathrm{MHz}\right) \delta \mathrm{ppm}$ : 7/12(S, 1H) ppm, 7/51 (dd, $1 \mathrm{H}$, $\mathrm{J}=6 / 295, \mathrm{~J}=2 / 165) ; 7 / 71(\mathrm{~d}, 1 \mathrm{H}, \mathrm{J}=2 / 115) ; 7 / 77(\mathrm{~d}, 1 \mathrm{H}, \mathrm{J}=8 / 455) ; 8 / 2(\mathrm{NH})$.

2.5.2 4-phenyl-1H-imidazole-2(3H)-thione (4b)

Pale yellow solid; m.p. $155 \mathrm{C}-158 \mathrm{C}$; Yield 92\%. FT-IR $(\mathrm{KBr}) \vee \max \left(\mathrm{cm}^{-1}\right): 3271 / 05 \mathrm{~cm}^{-1}(\mathrm{NH}) ; 3122 / 54 \mathrm{~cm}^{-1}$ (aromatic $\mathrm{C}-\mathrm{H}) ; 1633.59 \mathrm{~cm}^{-1}(\mathrm{C}=\mathrm{S}) .{ }^{1} \mathrm{H}-\mathrm{NMR}$ (DMSO, $\left.500 \mathrm{MHz}\right) \delta \mathrm{ppm}: 7 / 13-7 / 55(\mathrm{~m}, 5$ aromatic $\mathrm{H}) ; 7 / 26\left(\mathrm{~S},{ }^{1} \mathrm{H}\right) ; 9 / 04(2 \mathrm{NH})$. ${ }^{13} \mathrm{C}-\mathrm{NMR}$ (DMSO, 125MHz) $\delta$ ppm: 170/36 (C=S), 144/21 (imidazole C-N), 138/62(imidazole CH-N), 129/25, 128/45, 128/25, 125/61, 125/43 (aromatic CH).

2.5.3 5-pheynl thiazole 2-amine (3b)

Yellow solid; m.p. $254{ }^{\circ} \mathrm{C}-257^{\circ} \mathrm{C}$; Yield 89\%; ${ }^{1} \mathrm{H}-\mathrm{NMR}$ (DMSO, $\left.500 \mathrm{MHz}\right) \delta \mathrm{ppm}$ : 7/22 (S , 1H); 7/72 (d, 2H, J =7/3); $7 / 47(\mathrm{~m}, 3 \mathrm{H}) ; 8 / 8\left(\mathrm{NH}_{2}\right) \mathrm{ppm}$.

2.5.4 5-(4- methoxy phenyl) thiazole-2-amine (3c)

White solid; m.p. $205^{\circ} \mathrm{C}-207^{\circ} \mathrm{C}$; Yield 90\%; ${ }^{1} \mathrm{H}-\mathrm{NMR}$ (DMSO, $\left.500 \mathrm{MHz}\right) \delta \mathrm{ppm}: 3 / 60\left(\mathrm{CH}_{3}\right), 7 / 05\left(\mathrm{~d},{ }^{1} \mathrm{H}, \mathrm{J}=8 / 7\right.$ ); 7/09 $(\mathrm{S}, 1 \mathrm{H}) ; 7 / 15\left(\mathrm{~d},{ }^{1} \mathrm{H}, \mathrm{J}=7 / 65\right) ; 7 / 53\left(\mathrm{~d},{ }^{1} \mathrm{H}, \mathrm{J}=8\right) ; 7 / 66\left(\mathrm{~d},{ }^{1} \mathrm{H}, \mathrm{J}=13 / 76\right) ; 8 / 7(\mathrm{NH}) \mathrm{ppm}$.

2.5.5 4-(2',4'-dichlorophenyl)- ${ }^{1} \mathrm{H}$-imidazole-2 (3H)-thione (4a)

White solid; m.p. $145^{\circ} \mathrm{C}-150{ }^{\circ} \mathrm{C}$; Yield 87\%; FT-IR (KBr) $v \max \left(\mathrm{cm}^{-1}\right): 3450 / 41 \mathrm{~cm}^{-1}(\mathrm{NH}) ; 2925 / 81-3139 / 90 \mathrm{~cm}^{-1}$ (aromatic C-H); 1649/02 $\mathrm{cm}^{-1}(\mathrm{C}=\mathrm{S}) ; 1336-1367 \mathrm{~cm}^{-1}(\mathrm{C}-\mathrm{Cl}) ; 1461 / 94-1533 / 30 \mathrm{~cm}^{-1}$ (aromatic C=C). ${ }^{1} \mathrm{H}-\mathrm{NMR}$ (DMSO, $500 \mathrm{MHz}) \delta$ ppm: 7/08 (S, 1H); 7/44 (dd, 1H, J = 6/4; J = 2/1); 7/62 (d, 1H, J = 2/3); 7/81 (d, 1H, J = 8/5 Hz) ppm. ${ }^{13} \mathrm{C}-\mathrm{NMR}$ (DMSO, 125MHz) $\delta$ ppm: 167/78 (C=S); 142/77 (imidazole C-N); $132 / 52$ (imidazole CH-N); 131/62, 131/08 (aromatic C-Cl); 129/62,127/44, 125/31 (aromatic CH).

2.5.6 5-(3', 4'-dihydroxy phenyl) thiazole 2-amine (3d)

White solid; m.p. $245^{\mathrm{O}} \mathrm{C}-248{ }^{\circ} \mathrm{C}$; Yield 87\%; ${ }^{1} \mathrm{H}-\mathrm{NMR}$ (DMSO, $\left.500 \mathrm{MHz}\right) \delta$ ppm: 6/85 (d, ${ }^{1} \mathrm{H}, \mathrm{J}=8 / 135$ ); 6/91 (S, ${ }^{1} \mathrm{H}$ ); $7 / 04(\mathrm{dd}, 1 \mathrm{H}, \mathrm{J}=6, \mathrm{~J}=2 / 015) ; 7 / 11(\mathrm{~d}, 1 \mathrm{H}, \mathrm{J}=2 / 19) ; 9 / 1(\mathrm{NH}, 2 \mathrm{OH})$.

2.5.7 4-(3,4-dihydroxyphenyl)-1H-imidazole-2(3H)-thione (4d)

White solid; m.p. $110^{\circ} \mathrm{C}-120^{\circ} \mathrm{C}$; Yield 87\%; FT-IR (KBr) $v$ max $\left(\mathrm{cm}^{-1}\right)$ : $3743(\mathrm{O}-\mathrm{H}) ; 3305 / 76(\mathrm{NH}) ; 2790-3247$ (aromatic C-H); 1633/59 (C=S) cm ${ }^{-1} .{ }^{1} \mathrm{H}-\mathrm{NMR}$ (DMSO, $\left.500 \mathrm{MHz}\right) \delta \mathrm{ppm}: 5 / 26\left(\mathrm{~S},{ }^{1} \mathrm{H}\right) ; 6 / 78(\mathrm{t}, 1 \mathrm{H}) ; 7$ (dd, ${ }^{1} \mathrm{H}, \mathrm{J}=6 / 9$, $\mathrm{J}=1 / 3) ; 7.11\left(\mathrm{~d},{ }^{1} \mathrm{H}, \mathrm{J}=1 / 35\right) ; 8 / 35(2 \mathrm{OH}) ; 9 / 22(2 \mathrm{NH}) \mathrm{ppm} .{ }^{13} \mathrm{C}-\mathrm{NMR}$ (DMSO, 125MHz) $\delta \mathrm{ppm}: 169 / 63(\mathrm{C}=\mathrm{S}) ; 146 / 43$ (imidazole C-N); 145/58, 143/09 (aromatic C-OH); 122/41 (aromatic $\mathrm{C}^{\circ} 4$ ); 117/39 (imidazole CH-N); 115/92, 113/56, 113/28, (aromatic CH).

2.5.8 4-(4'-methoxy phenyl)- ${ }^{1} \mathrm{H}$-imidazole-2(3H)-thione (4c)

Pale yellow solid; m.p. $190{ }^{\circ} \mathrm{C}-194^{\circ} \mathrm{C}$; Yield 91\%;FT-IR (KBr) $v$ max $\left(\mathrm{cm}^{-1}\right): 3382 / 91(\mathrm{C}-\mathrm{H}$ in Me-O-); $3122 / 54(\mathrm{NH})$; 2746/44- 2989/46 (aromatic CH); 1629/74 (C=S) cm ${ }^{-1} .{ }^{1} \mathrm{H}-\mathrm{NMR}$ (DMSO, $\left.500 \mathrm{MHz}\right) \delta \mathrm{ppm:} \mathrm{3/74} \mathrm{(S,} \mathrm{CH3-O);} \mathrm{6/98} \mathrm{(d,}$ $1 \mathrm{H}, \mathrm{J}=6 / 6) ; 7 / 09(\mathrm{~S}, 1 \mathrm{H}) ; 7 / 15(\mathrm{~d}, 1 \mathrm{H}, \mathrm{J}=6 / 2) ; 7 / 62(\mathrm{~d}, 2 \mathrm{H}, \mathrm{J}=6 / 9) ; 9 / 13(2 \mathrm{NH}) .{ }^{13} \mathrm{C}-\mathrm{NMR}$ (DMSO, 125MHz) $\delta \mathrm{ppm}$ : 170/32 (C=S); 160/14 (imidazole C-N); 143/68 (aromatic C-OMe); 138/54 (imidazole CH-N); 120/77 (aromatic $\mathrm{C}^{\circ} 4$ ); 128/6, 127/27, 125/5, 114/48 (aromatic CH); 55/45 (OMe).

2.5.9 4-(4'-bromo phenyl)- ${ }^{1} \mathrm{H}$-imidazole-2(3H)-thione (4e)

White solid; m.p. $186-190{ }^{\circ} \mathrm{C}$; yield $84 \%$; Formation of this synthesized compound was confirmed by thin layer chromatography (TLC).

2.5.10 5-(3',4'-dihydroxy phenyl) thiazole 2- thion Using Ionic Liquid Catalyst (3d)

White solid; m.p. $254-258^{\circ}$ C; Yield $92 \%$ Formation of this synthesized compound was confirmed by thin layer chromatography (TLC) and comparing with the synthesized compound when $\mathrm{MeOH}$ was applied as the catalyst. 


\subsubsection{5-(2',4'-dichloro phenyl)-thiazole 2-amine Using Ionic Liquid Catalyst (3a)}

White solid; m.p. $206^{\mathrm{O}} \mathrm{C}-215^{\mathrm{O}} \mathrm{C}$; Yield $94 \%$; Formation of this synthesized compound was confirmed by thin layer chromatography (TLC) and comparing with the synthesized compound when DABCO was applied as the catalyst.

\subsubsection{5-(2',4'-dichloro phenyl)-thiazole 2-amine Using Sodium Hydroxide (3a)}

White solid; m.p. $210^{\circ} \mathrm{C}-215^{\circ}$ C; Yield $84 \%$; Formation of this synthesized compound was confirmed by thin layer chromatography (TLC) and comparing with the synthesized compound when DABCO was applied as the catalyst (3a).

\section{Results and Discussion}

As shown in scheme (1), we quickly and efficiently synthesized 1,3-diazole and thiazole derivatives ( $4 \mathrm{a}$-d, $3 \mathrm{a}$-d) by refluxing some 2-holo acetophenone derivatives $\left(1_{\mathrm{a}-\mathrm{e}}\right)$ and thiourea (2) using water as reaction solvent and different kinds of catalysts. Compared to reported methods of thiazole and 1,3-diazole synthesis (Ghodse \& Telvekar, ,2015; Zhao et al., 2002) which employed toxic organic solvents and they were time-taking or expensive, this procedure is less hazardous, less toxic, cheap and environment friendly. The occurred reactions in this procedure, lead to produce desired compounds with high yields of $85-94 \%$ (table 1). The reaction time was short (6h). All reaction mixtures were cooled at room temperature and the precipitate was filtered easily. In FT-IR spectra of the synthesized 1, 3- diazole derivatives, the adsorption bands of $\mathrm{C}=\mathrm{S}$ and $\mathrm{NH}$ were observed respectively within $1629.74 \_1649.02 \mathrm{~cm}^{-1}$ and 3122.54_3450.41 $\mathrm{cm}^{-1}$. In ${ }^{1} \mathrm{H}-\mathrm{NMR}$ spectra of 1, 3-diazole-2-thion and thiazole 2-amine derivatives, the aromatic hydrogens of phenyl ring and 1,3-diazole-2-thion and thiazole 2-amine rings appeared within 7-8 ppm as singlets, doublets, doublet of doublets or multiplets according to the type of hydrogen. The absorption band of $\mathrm{NH}$ and $\mathrm{NH}_{2}$ groups in 1,3-diazole-2-thion and thiazole 2-amine derivatives were observed in the region of higher than $8 \mathrm{ppm}(8-10 \mathrm{ppm})$ and these absorption bands were disappeared in $\mathrm{D}_{2} \mathrm{O}$ shake- ${ }^{1} \mathrm{H}-\mathrm{NMR}$ which can confirm the predicted structures of the synthesized compounds. ${ }^{13} \mathrm{C}$-NMR chemical shifts for the compounds were displayed in their expected regions.

Using an ionic liquid as catalyst, the reaction yields the same compounds as the case of using DABCO and sodium hydroxide, but the reaction time was decreased and the yield was increased significantly.

As it was shown in the table 1 and scheme 1, thiazole derivatives were synthesized in basic $\mathrm{pH}$ using basic catalysts or solvent such as DABCO, $\mathrm{NaOH}$, ionic liquid and diazole derivatives were obtained in acidic PH when PTSA and $\mathrm{H}_{2} \mathrm{SO}_{4}$ were applied as catalysts. In contrast of above conditions when we used methanol as catalyst and solvent both products, diazoles and thiazoles were appeared.

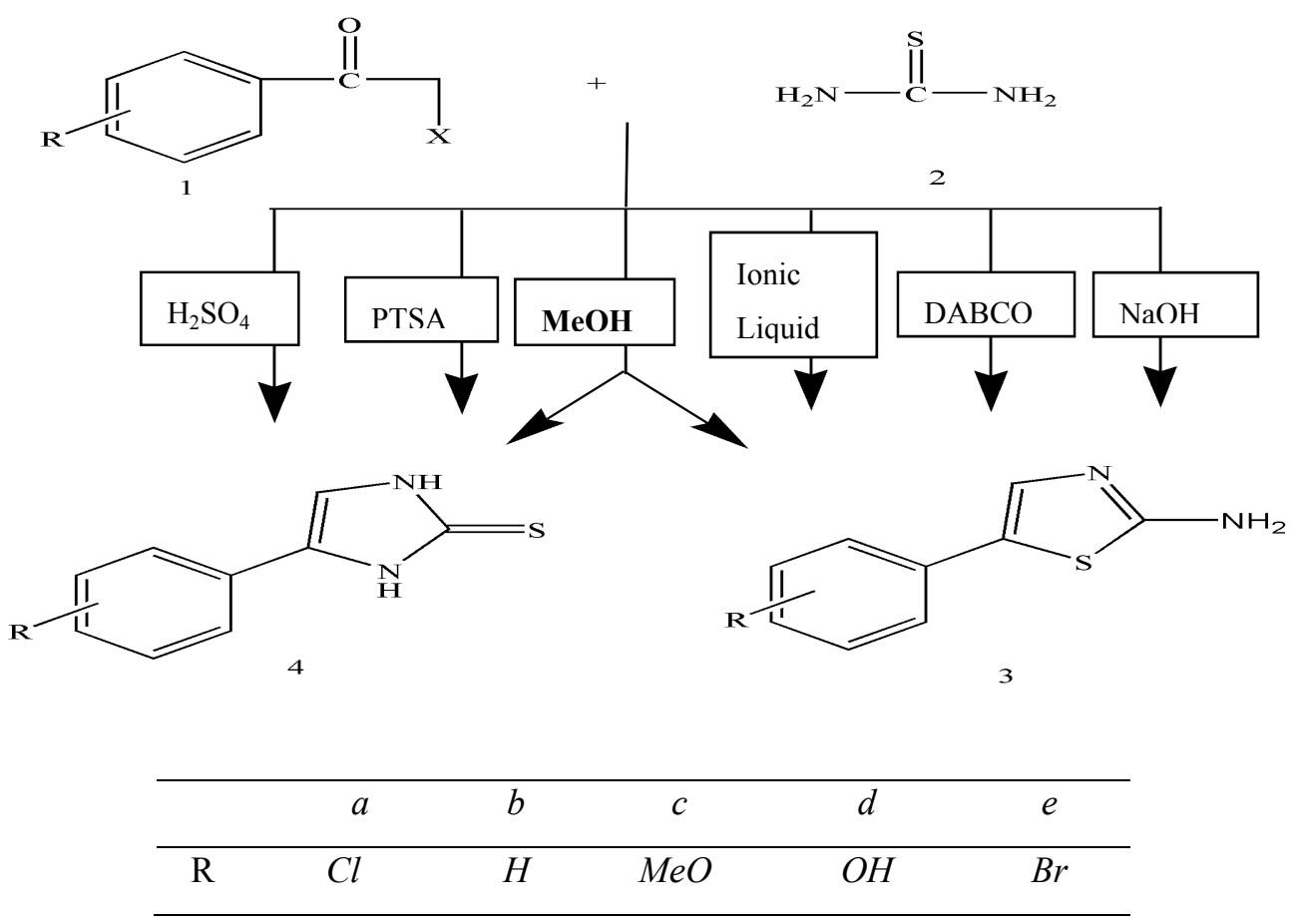

Scheme 1. Reagents and conditions 
Table 1. Synthesis of 10e-p and 11e-p using green chemistry procedures

\begin{tabular}{|c|c|c|c|c|}
\hline Entry & $\mathrm{R}$ & catalyst & Time (hour) & Yield (\%) \\
\hline $3 a$ & 2',4'-dichloro & DABCO & 4 & 88 \\
\hline $3 b$ & $\mathrm{H}$ & DABCO & 5 & 89 \\
\hline $3 c$ & 4'-methoxy & $\mathrm{DABCO}$ & 6 & 90 \\
\hline $3 d$ & 3',4'-dihydroxy & Methanol & 5 & 87 \\
\hline $3 d$ & 3',4'-dihydroxy & Ionic liquid & 3 & 92 \\
\hline $3 a$ & 2',4'-dichloro & Ionic liquid & 3 & 94 \\
\hline $3 a$ & 2',4'-dichloro & $\mathrm{NaOH}$ & 5 & 84 \\
\hline $4 b$ & $\mathrm{H}$ & PTSA & 4 & 92 \\
\hline $4 a$ & 2',4'-dichloro & PTSA & 4 & 87 \\
\hline $4 d$ & 3',4'-dihydroxy & $\mathrm{H}_{2} \mathrm{SO}_{4}$ & 6 & 87 \\
\hline $4 \mathrm{c}$ & 4'-methoxy & PTSA & 5 & 91 \\
\hline $4 \mathrm{e}$ & 4'-bromo & PTSA & 6 & 84 \\
\hline
\end{tabular}

\subsection{The Possible Mechanism to Synthesize the Yielded Compounds}

In acidic media (by the use of PTSA, $\mathrm{H}_{2} \mathrm{SO}_{4}$ as catalyst), the reaction starts with a nucleophilic attack of nitrogen non-bonding pair in thiourea to $-\mathrm{CH}_{2}$ in acetophenone derivatives and halogen is pushed off as the leaving group. An intramolecular nucleophilic attack of $\mathrm{NH}_{2}$ to carbonyl group is occurred and the cycle of imidazole is formed. After $\mathrm{H}_{2} \mathrm{O}$ molecule elimination, $\pi$ bonds are shifted to maintain the aromaticity of imidazole structure (Scheme 2).

In basic media (by the use of $\mathrm{DABCO}, \mathrm{NaOH}$, Ionic liquid as catalyst), the reaction proceeds like mechanism for imidazole synthesis. According to resonance between sulfur and nitrogen, thiocarbonyl bond is opened up and sulfur gets nagative charge. Then it causes the second nucleophilic attack to carbonyl group. At the end, the aromatic compound of thiazol is formed by elimination of $\mathrm{H}_{2} \mathrm{O}$ molecule and a proton $\left(\mathrm{H}^{+}\right)$(scheme 3 ).

In the case of using cholin chloride urea as ionic liquid catalyst, the reaction is carried on in basic media. The differences in the sizes of anions and cations in the ionic liquids, leads to weak ionic bonding, therefore chlorin which is an anion group can be free in media. Chlorin with the negative charge makes nitrogen suitable for starting the nucleophilic attack.

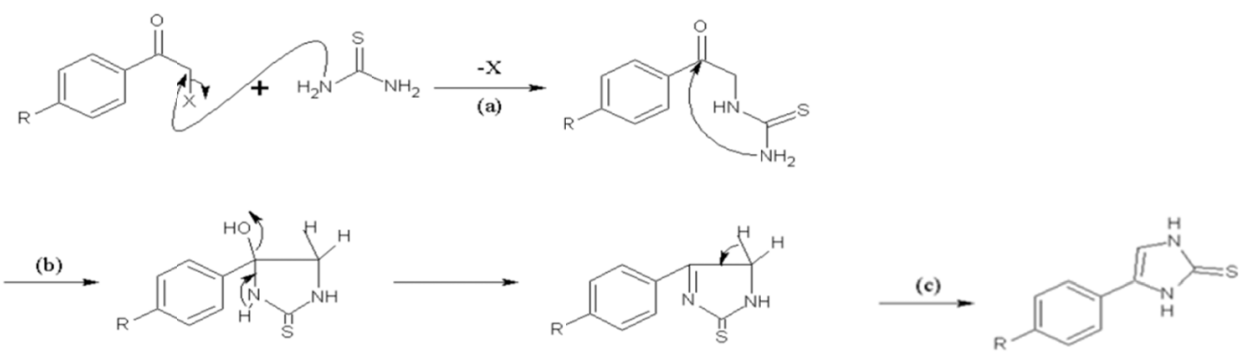

Scheme 2. Imidazole synthesis in acidic media

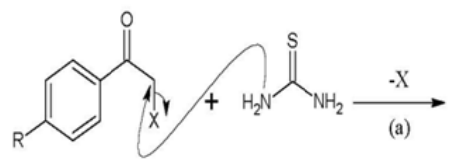<smiles>Cc1ccc(-c2cnc(N)s2)cc1</smiles>
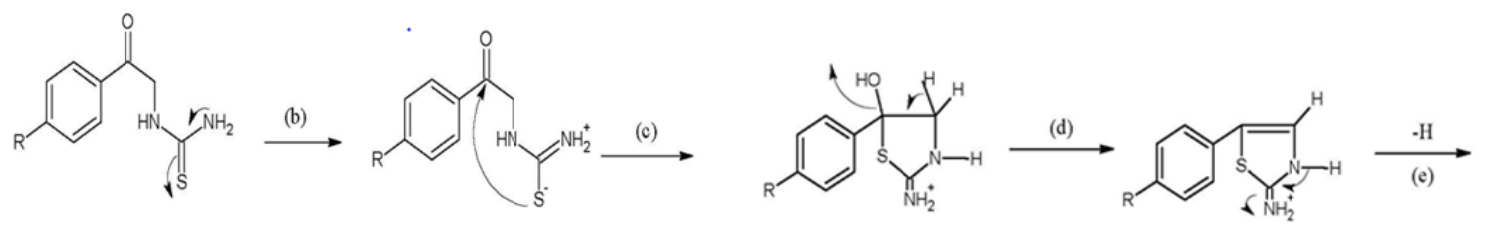

Scheme 3. Thiazole synthesis in basic media

In the second part of this study antibacterial activities of the synthesized compounds were investigated. The results have shown that the compounds $4 \mathrm{a}, 4 \mathrm{~b}, 3 \mathrm{~b}, 3 \mathrm{a}$ (the first 4 compounds) had the maximum antibacterial activity against 
Escherichia Coli compared to tetracycline and imipenem antibiotics. The compound 3a showed the best antibacterial activity against gram positive bacterias Staphylococcus aureus and Bacillus Subtilis compared to both applied antibiotics and acceptable antibacterial activity against gram negative bacteria Serratia marcescens compared to tetracycline. The results of this part have been shown in the table 2.

Table 2. Antibacterial activities of synthesized compounds

\begin{tabular}{cccccc}
\hline Compounds & Functional groups & E. Coli & S. aureus & S. marcescens & B. Subtilis \\
\hline $4 \mathrm{a}$ & $2 \mathrm{Cl}$ & 18 & 15 & 12 & 10 \\
$4 \mathrm{~b}$ & $\mathrm{H}$ & 20 & 17 & 21 & 20 \\
$3 \mathrm{~b}$ & $\mathrm{H}$ & 20 & 15 & 27 & 12 \\
$3 \mathrm{a}$ & $2 \mathrm{Cl}$ & 29 & 35 & 18 & 21 \\
$3 \mathrm{a}$ & $2 \mathrm{Cl}$ & 10 & 11 & 10 & 12 \\
$4 \mathrm{e}$ & $\mathrm{Br}$ & 7 & 9 & 10 & 10 \\
$4 \mathrm{~d}$ & $2 \mathrm{OH}$ & 9 & 0 & 10 \\
$4 \mathrm{~d}$ & $2 \mathrm{OH}$ & 10 & 0 & 8 & 7 \\
$3 \mathrm{~d}$ & $2 \mathrm{OH}$ & 0 & 8 & 17 & 10 \\
$4 \mathrm{c}$ & $\mathrm{MeO}$ & 0 & 10 & 12 & 10 \\
$3 \mathrm{c}$ & $\mathrm{MeO}$ & 0 & 11 & 12 & 10 \\
$3 \mathrm{~d}$ & $2 \mathrm{OH}$ & 11 & 10 & 10 & 10 \\
Tetracycline & - & 12 & 21 & 9 & 10 \\
Imipeneme & - & 16 & 24 & 30 & 0
\end{tabular}

In conclusion, we have developed a facile, efficient and green method for the synthesis of 1,3-diazole and thiazole derivatives by refluxing acetophenone derivatives and thiourea in water medium and various types of catalysts. Then, in a second part, antibacterial activities of the resulting compounds were studied. The antibacterial activities of the compounds have demonstrated appropriate results compared to common antibiotics. Compared to the previously reported methodologies, our protocol offers considerable benefits, including that it has a simple procedure, is environmentally friendly, produces high yields.

\section{References}

Afradi, M., Foroughifar, N., \& Moghanian, H. (2016). L-Proline N-sulfonic acid-3, 4-dihydropyrimidine-2-(1H)-thiones under solvent-free conditions. RSC Advances. https://doi.org/10.1039/C6RA10558K

Afradi, M., Foroughifar, N., Pasdar, H., \& Moghanian, H. (2016). Facile green one-pot synthesis of novel thiazolo [3, 2-a] pyrimidine derivatives using Fe3O4@ L-arginine and their biological investigation as potent antimicrobial agents. Applied Organometallic Chemistry. https://doi.org/10.1002/aoc.3683

Ashish, B., \& Pandeya, S. (2011). Various approaches for synthesis of imidazole derivatives. IJRAP, 2(4), 1124-1129.

Ayati, A., Emami, S., Asadipour, A., Shafiee, A., \& Foroumadi, A. (2015). Recent applications of 1, 3-thiazole core structure in the identification of new lead compounds and drug discovery. European Journal of Medicinal Chemistry, 97, 699-718. https://doi.org/10.1016/j.ejmech.2015.04.015

Bakavoli, M., Beyzaie, H., Rahimizadeh, M., Eshghi, H., \& Takjoo, R. (2009). Regioselective synthesis of new 2-(E)-cyano (thiazolidin-2-ylidene) thiazoles. Molecules, 14(12), 4849-4857. https://doi.org/10.3390/molecules 14114849

Chawla, A., Sharma, A., \& Kumar, S. A. (2012). Review: A convenient approach for the synthesis of imidazole derivatives using microwaves. Synthesis, 5(6), 7.

El-Sehrawi, H. M., Soliman, D. H., Khalifa, M. M., \& El-Bakry, O. M. (2015). Synthesis, Biological Evaluation and 2D-QSAR Studies of Novel 6-Oxo-Pyridine-3-Carboxamide Derivatives as Antimicrobial and Antifungal Agents. International Journal of Chemistry, 8(1), 49. https://doi.org/10.5539/ijc.v8n1p49

Foroughifar, N., Mobinikhaledi, A., Ebrahimi, S., Moghanian, H., Fard, M. A. B., \& Kalhor, M. (2009). Synthesis of a new class of azathia crown macrocycles containing two 1, 2, 4-triazole or two 1, 3, 4-thiadiazole rings as subunits. Tetrahedron Letters, 50(7), 836-839. https://doi.org/10.1016/j.tetlet.2008.12.014

Ghasemi, B., Beyzaei, H., Hashemi, S. H., \& Majidiani, H. (2016). Study of Antibacterial Effect of Novel Thiazole, Imidazole and Tetrahydropyridine Derivatives against Escherichia coli. Journal of Medical Bacteriology, 4(5,6), $7-12$. 
Ghodse, S. M., \& Telvekar, V. N. (2015). Synthesis of 2-aminothiazole derivatives from easily available thiourea and alkyl/aryl ketones using aqueous $\mathrm{NaICl} 2$. Tetrahedron Letters, 56(2), 472-474. https://doi.org/10.1016/j.tetlet.2014.11.140

Holla, B. S., Malini, K. V., Rao, B. S., Sarojini, B. K., \& Kumari, N. S. (2003). Synthesis of some new 2, 4-disubstituted thiazoles as possible antibacterial and anti-inflammatory agents. European Journal of Medicinal Chemistry, 38(3), 313-318. https://doi.org/10.1016/S0223-5234(02)01447-2

Miqdad, O. A., Abunada, N. M., Hassaneen, H. M., \& Samaha, A. S. M. A. (2011). Synthesis and biological activity evaluation of some new heterocyclic spirocompounds with imidazolinone and pyrazoline moieties. International Journal of Chemistry, 3(4), 20. https://doi.org/10.5539/ijc.v3n4p20

Mishra, R., Tomer, I., Priyanka, N., Sharma, K., \& Jha, K. K. (2012). Synthe sis and antimicrobial evaluation of some novel thiazole derivatives. Pharm Sin, 3, 361-366.

Mobinikhaledi, A., Foroughifar, N., \& Bodaghi, F. M. A. (2010). Eco-friendly and efficient synthesis of pyrano [2, 3-d] pyrimidinone and tetrahydrobenzo [b] pyran derivatives in water. Synthesis and Reactivity in Inorganic, Metal-Organic, and Nano-Metal Chemistry, 40(3), 179-185.

Mobinikhaledi, A., Foroughifar, N., \& Kalhor, M. (2010). An efficient synthesis of Schiff bases containing benzimidazole moiety catalyzed by transition metal nitrates. Turkish Journal of Chemistry, 34(3), 367-374. http://dx.doi.org/10.3906/kim-0906-49

Mobinikhaledi, A., Foroughifar, N., Kalhor, M., \& Mirabolfathy, M. (2010). Synthesis and antifungal activity of novel 2 - benzimidazolylimino - 5 - arylidene - 4 - thiazolidinones. Journal of Heterocyclic Chemistry, 47(1), 77-80. http://dx.doi.org/ 10.1002/jhet.264

Narender, M., Reddy, M. S., Sridhar, R., Nageswar, Y. V. D., \& Rao, K. R. (2005). Aqueous phase synthesis of thiazoles and aminothiazoles in the presence of $\beta$-cyclodextrin. Tetrahedron Letters, 46(35), 5953-5955. https://doi.org/10.1016/j.tetlet.2005.06.130

Olivier-Bourbigou, H., Magna, L., \& Morvan, D. (2010). Ionic liquids and catalysis: Recent progress from knowledge to applications. Applied Catalysis A: General, 373(1), 1-56. https://doi.org/10.1016/j.apcata.2009.10.008

Ratti, R. (2014). Ionic Liquids: Synthesis and Applications in Catalysis. Advances in Chemistry, 2014. https://doi.org/10.1155/2014/729842

Safari, J., Akbari, Z., \& Naseh, S. (2012). Nanocrystalline MgAl 2 O 4 as an efficient catalyst for one-pot synthesis of multisubstituted imidazoles under solvent-free conditions. Journal of Saudi Chemical Society. https://doi.org/10.1016/j.jscs.2012.10.012

Selva, M., Perosa, A., Guidi, S., \& Cattelan, L. (2016). Ionic liquids as transesterification catalysts: applications for the synthesis of linear and cyclic organic carbonates. Beilstein Journal of Organic Chemistry, 12(1), 1911-1924. https://doi.org/10.3762/bjoc.12.181

Shalini, K., Sharma, P. K., \& Kumar, N. (2010). Imidazole and its biological activities: A review. Der Chemica Sinica, $1(3), 36-47$.

Yavari, I., Sayyed-Alangi, S. Z., Hajinasiri, R., \& Sajjadi-Ghotbabadi, H. (2009). A one-pot synthesis of functionalized ethyl 1,3-thiazole-5-carboxylates from thioamides or thioureas and 2-chloro-1,3-dicarbonyl compounds in an ionic liquid. Monatshefte für Chemie-Chemical Monthly, 140(2), 209-211. https://doi.org/10.1007/s00706-008-0065-7

Zhao, D. B., Wu, M., Kou, Y., \& Min, E. Z. (2002). Ionic liquids: applications in catalysis. Catalysis today, 74(1), 157-189. https://doi.org/10.1016/S0920-5861(01)00541-7

\section{Copyrights}

Copyright for this article is retained by the author(s), with first publication rights granted to the journal.

This is an open-access article distributed under the terms and conditions of the Creative Commons Attribution license (http://creativecommons.org/licenses/by/4.0/). 